\title{
Proteomics research and related functional classification of liquid sclerotial exudates of Sclerotinia ginseng
}

\author{
Dan Wang ${ }^{1}$, Jun Fan Fu ${ }^{\text {Corresp.. }}{ }^{1}$, Ru Jun Zhou ${ }^{1}$ ， Zi Bo Li ${ }^{1}$, Yu Jiao Xie ${ }^{1}$ \\ ${ }^{1}$ Department of Plant Protection, Shenyang Agricultural University, Shenyang, Liaoning, China \\ Corresponding Author: Jun Fan Fu \\ Email address: fujunfan@163.com
}

Sclerotinia ginseng is a necrotrophic soil pathogen that mainly infects the root and basal stem of ginseng, causing serious commercial losses. Sclerotia, which are important in the fungal life cycle, are hard, asexual, resting structures that can survive in soil for several years. Generally, sclerotium development is accompanied by the exudation of droplets. Here, the yellowish droplets of $S$. ginseng were first examined by sodium dodecyl sulfatepolyacrylamide gel electrophoresis, and the proteome was identified by a combination of different analytical platforms. A total of 59 proteins were identified and classified into six categories: carbohydrate metabolism (39\%), oxidation-reduction process (12\%), transport and catabolism (5\%), amino acid metabolism (3\%), other functions (18\%), and unknown protein $(23 \%)$, which exhibited considerable differences in protein composition compared with droplets of $S$. sclerotium. In the carbohydrate metabolism group, several proteins were associated with sclerotium development, particularly fungal cell wall formation. The pathogenicity and virulence of the identified proteins are also discussed in this report. The findings of this study may improve our understanding of the function of exudate droplets as well as the life cycle and pathogenesis of $S$. ginseng. 
1 Proteomics research and related functional classification of liquid sclerotial exudates from

2 Sclerotinia ginseng

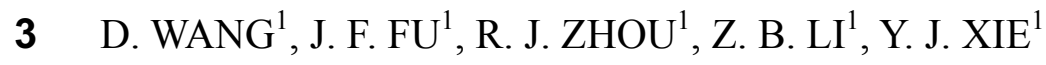

4

$5 \quad{ }^{1}$ Department of Plant Protection, Shenyang Agricultural University, Shenyang, Liaoning, PR

6 China

7

8 Corresponding Author:

$9 \quad$ J. $\mathrm{FU}^{1}$

10 Room 120, Dongling Road, Shenhe District, Shenyang City, Liaoning Prov., 110866, PR China

11 Email address: fujunfan@163.com 
12 Proteomics research and related functional classification of liquid sclerotial exudates from

Sclerotinia ginseng

14

\author{
Dan WANG, Junfan FU*, Rujun ZHOU, Zibo LI, Yujiao XIE
}

15 Department of Plant Protection, Shenyang Agricultural University, Shenyang 110866, PR China

16 ABSTRACT

17 Sclerotinia ginseng is a necrotrophic, soil pathogen that mainly infects the root and basal stem of

18 ginseng, causing serious commercial losses. Sclerotia, which are important in the fungal life

19 cycle, are hard, asexual, resting structures that can survive in soil for many years. Generally,

20 sclerotium development is accompanied by the exudation of droplets, which is a common feature.

21 Here the yellowish droplets of $S$. ginseng were first examined by sodium dodecyl sulfate

22 polyacrylamide gel electrophoresis, and the proteome was identified by integration of different

23 analytical platforms. The results showed that 59 proteins were identified and classified into six

24 categories: carbohydrate metabolism (39\%), oxidation-reduction process (12\%), transport and

25 catabolism (5\%), amino acid metabolism (3\%), other functions (18\%), and unknown protein

26 (23\%), which exhibited considerable difference compared to droplets of S. sclerotium. In the

27 carbohydrate metabolism group, many proteins were associated with sclerotium development,

28 especially fungal cell wall formation. The pathogenicity and virulence of the identified proteins

29 are also discussed in this paper. The results may facilitate our understanding of the function of

30 exudate droplets, and lay a foundation for better understanding of the life cycle and pathogenesis

31 of S. ginseng.

32

33 INTRODUCTION

34 Ginseng (Panax ginseng C. A. Meyer) is a perennial medicinal herb in the Araliaceae family 
35 that is mainly distributed in China, North Korea, South Korea, Japan and Russia. As a precious

36 medicinal material, it is widely used in the fields of medical care, health care, and the chemical

37 industry. It is highly valued because its medicinal ingredients have extracts containing

38 ginsenosides (Sun 2011; Wan et al. 2015; Wang et al. 2016), essential oil, polysaccharides (Wan

39 et al. 2015), and peptides (Sun 2011). These make ginseng possessing antitumor (Sun 2011;

40 Zhou et al. 2014), immunoregulatory, antioxidant (Sun 2011; Yu et al. 2014), antihyperglycemic

41 (Jiao et al. 2014), and antimalarial activities (Han et al. 2011). China is the largest ginseng

42 production area, with a yield of up to $70 \%$ of the world's output. In recent years, with the

43 increasing recognition and demand of ginseng, the artificial cultivation area of ginseng has

44 continuously expanded, which could easily lead to disease epidemic.

45 Because the roots are the main medicinal parts of ginseng, root disease by various soil 46 pathogens including Cylindrocarpon, Pythium, and Sclerotinia (Cho et al. 2013) cause

47 inestimable economic losses. In fact, $S$. ginseng has already given rise to a serious epidemic

48 disease in northeast China, with an incidence ranging from $10 \%$ to $15 \%$, and up to $20 \%$ in severe

49 cases. Mycelium is the main source of infection and can directly infect the root and basal part of

50 the ginseng stem. Symptoms of $S$. ginseng infection first includes a rusty brown-colored

51 epidermis, water-soaked lesions, and dissolved pith, which eventually leave the ginseng

52 epidermis; later, sclerotia can be found on the surface of the infected root tissues and basal part

53 of the stems. Sclerotia are hard, asexual, resting structures (Erental et al. 2008) that use

54 overwintering as a way to survive in soil for several years (Adams and Ayers 1979; Kwon et al.

55 2014). Under adverse conditions, the mycelium of $S$. ginseng stop its vegetative growth and

56 begin to coalesce into sclerotia. Sclerotia, as common dissemination structures of many

57 important agricultural crop pathogens, such as $S$. sclerotiorum, Sclerotium rolfsii, B. cinerea, and 
58 Claviceps purpurea (Erental et al. 2008), play important roles in their niche.

59 Sclerotia development is usually divided into three stages: sclerotia initial (SI), sclerotia

60 developing (SD), and sclerotia mature (SM) (Patsoukis and Georgiou 2007). The formation of

61 liquid droplets by sclerotia is a common feature during sclerotia development (Cooke 1969;

62 Colotelo 1973; Liang et al. 2010). The very beginning of liquid droplet occurrence is observed

63 on the surface of aerial hyphae at the initial stage, and the droplets increase in size during growth

64 of the sclerotia. At the SD stage of development, exudate droplets can be clearly observed by the

65 naked eye on the surface of interwoven hyphae. Concomitantly with mature features, including 66 surface delimitation, internal consolidation, and pigmentation (Erental et al. 2008), the droplets

67 reach maximum quantity but disappear upon further culture. The dehydration and thickening of

68 cell walls, polymerization of soluble compounds, and decreased moisture in tissues may all be

69 reasons to condense the active exudation of water on the surface of sclerotia (Daly et al. 1967;

70 Willetts 1971; Chet and Henis 1975; Willetts and Bullock 1992). However, these droplets are

71 only observed in culture and not under field conditions, possibly because of the combined effects

72 of air-drying, the absorption of soil, and the recycling of exudates needed for sclerotia

73 development (Pandey et al. 2007). After the droplets disappear, a copious dried-up deposit

74 consisting of membranous material is left on the sclerotial surface (Colotelo et al. 1971).

75 Exudation has a very complex composition, as it contains many kinds of substances such as

76 soluble carbohydrates, phenol oxidase, various salts, amino acids, proteins, cations, lipids,

77 ammonia, and enzymes in S. sclerotiorum (Cooke 1969, Jones 1970, Colotelo 1971); these

78 ingredients can reflect function to a certain extent. Although there has been little research on the

79 function of exudate droplets, studies should be performed due to their physiological significance.

80 With excess soluble carbohydrates released in a direct or converted way during effluence of 
81 exudate droplets from sclerotia, exudate droplets can maintain the internal physiological balance

82 of sclerotia through a selective mechanism (Cooke 1969). The carbohydrates in droplets may

83 have a significant influence on long-term survival of the sclerotia (Daly et al. 1967; Willetts 1971;

84 Chet and Henis 1975; Willetts and Bullock 1992). With the exception of carbohydrates, some

85 other constituents in exudate droplets are also reabsorbed and probably utilized by sclerotial

86 tissues (Colotelo 1978). Sclerotial size, weight, and germination are affected by the depletion of

87 exudate droplets during sclerotia development (Singh et al. 2002). Studies have shown that

88 pathogenicity is another important property of exudate droplets, and some proteins may be

89 involved in pathogen development and virulence (Liang et al. 2010). In addition, the metabolites

90 of exudate droplets such as phenolic acids from Rhizoctonia solani contribute to their antifungal,

91 phytotoxic, and antioxidant activities (Aliferis and Jabaji 2010).

92 To gain a better understanding of exudate function, especially its role in defense against

93 pathogens, sclerotium development and virulence, a proteome-level study was performed. To the

94 best of our knowledge, there has been no detailed analysis about proteins in the exudates of $S$.

95 ginseng. Moreover due to the significance of ginseng in herbal health care, it is imperative to

96 research the exudation of $S$. ginseng. In this study, the identified proteins were classified and

97 their functions were discussed.

98

99 MATERIALS AND METHODS

100 Fungal isolate and culture conditions. The strain (QY-6) was collected from Dasuhe Village,

101 Qingyuan County, Liaoning Province, China on July 16, 2016. To make the separation of

102 pathogens easier, the invaded tissues were stored at a low temperature $\left(4^{\circ} \mathrm{C}\right)$ for several days to

103 induce more obvious symptoms. After isolation and purification, the pathogen was cultured on 
104 potato dextrose agar (PDA) (200 g/L potato, $20 \mathrm{~g} / \mathrm{L}$ dextrose, $20 \mathrm{~g} / \mathrm{L}$ agar power, sterilized) in a

105 Petri dish, and incubated at optimum temperature $\left(20 \pm 1^{\circ} \mathrm{C}\right)$ in the dark until it became an active

106 mature sclerotium for the collection of exudates.

107

108 Generation and collection of exudates. The mature sclerotia that formed on the culture medium

109 were shaped like an inverted bowl buckled when it reached maturation, and stage droplets

110 adhered to the surface of sclerotia in the same manner that sweat sticks to people. The agar block

111 with mycelia was incubated at optimum temperature $\left(20 \pm 1^{\circ} \mathrm{C}\right)$ for 5 days, after which a $5 \mathrm{~mm}$

112 diameter mycelia plug was cut along the edge of the fresh colony to start a new round of growth

113 for the collection of exudates. The exudates were sucked from the surface of the sclerotia with a

114 disposable blood collection tube $(20 \mu \mathrm{L})$, and the liquid was stored in a $1.5 \mathrm{~mL}$ microcentrifuge

115 tube (GEB, Torrance, CA, USA) at $-20^{\circ} \mathrm{C}$ for subsequent experiments. To collect a minimum

116 amount of sclerotial exudates, approximately 600 Petri dishes with QY-6 isolate were cultured

117 and divided into three batches, after which the droplets were collected and mixed together for

118 further analysis.

119

120 Protein preparation. The exudate droplets were ultrafiltered and concentrated to $300 \mu \mathrm{L}$. Added

121 to 1 volume of protein solution 4 volumes of cold acetone. Mixed and kept overnight at $-20^{\circ} \mathrm{C}$.

122 Spun the mixture $10 \mathrm{~min}$ at $4^{\circ} \mathrm{C}$ in microfuge at speed $12000 \mathrm{~g}$. Carefully discharged supernatant

123 and retained the pellet: dried tube by inversion on tissue paper. Dried samples under dry air to

124 eliminate any acetone residue. In order to dissolve the protein of the dry pellet, added $50 \mu \mathrm{L}$

125 sample lysate (1\% DTT, 2\% SDS, 10\% glycerine, $50 \mathrm{mM}$ Tris-HCl, pH6.8) in the dry pellet at

126 room temperature for $4 \mathrm{~h}$. Spun the protein solution $15 \mathrm{~min}$ at room temperature in microfuge at 
127 speed $12000 \mathrm{~g}$ and retained the supernatant, which contained total protein. Stored the supernatant

128 of total protein at $-80^{\circ} \mathrm{C}$.

129

130 SDS-PAGE. For one-dimensional SDS-PAGE, $30 \mu \mathrm{g}$ protein sample was added to a $1.5 \mathrm{~mL}$

131 eppendorf tube, mixed with an equal volume of denaturing sample buffer, and placed in boiling

132 water for $5 \mathrm{~min}$. Then samples were subjected to SDS-PAGE on $12 \%$ gels. Electrophoresis was

133 performed at $80 \mathrm{~V}$ until the bromophenol blue had reached the separating gel, after which the

134 voltage was increased to $120 \mathrm{~V}$. After electrophoresis, the gel was stained with Coomassie

135 Brilliant Blue G-250 for $6 \mathrm{~h}$ and then destained with destaining solution $\left(25 \mathrm{mM} \mathrm{NH}_{4} \mathrm{HCO}_{3}\right.$,

$13650 \%$ acetonitrile aqueous solution).

137

138 In-gel protein digestion. Protein samples for in-gel digestion were prepared according to

139 Katayama et al. (2001) with some minor modifications. Protein bands were excised from the

140 stained 1-DE gels and placed the gel pieces in a $1.5 \mathrm{ml}$ eppendorf tube. Added $200 \mu \mathrm{L}$ of the

141 ultrapure water once time and rinsed the gel pieces twice. Removed the ultrapure water and

142 added $200 \mu \mathrm{L}$ of the destaining solution $\left(25 \mathrm{mM} \mathrm{NH}_{4} \mathrm{HCO}_{3}, 50 \%\right.$ acetonitrile aqueous solution)

143 at room temperature for $30 \mathrm{~min}$. Removed the destaining solution and added dehydration

144 solution 1 (50\% acetonitrile solution) for $30 \mathrm{~min}$. Removed the dehydration solution 1 and

145 added dehydration solution 2 (100\% acetonitrile solution) for $30 \mathrm{~min}$. Removed the dehydration

146 solution 2 and added reduction solution $1\left(25 \mathrm{mM} \mathrm{NH}_{4} \mathrm{HCO}_{3}\right.$ and $\left.10 \mathrm{mM} \mathrm{DTT}\right)$ at $57^{\circ} \mathrm{C}$ for $1 \mathrm{~h}$.

147 Removed the reduction solution 1 and added reduction sulution $2\left(25 \mathrm{mM} \mathrm{NH}_{4} \mathrm{HCO}_{3}\right.$ and $50 \mathrm{mM}$

148 iodoacetamide) at room temperature for $30 \mathrm{~min}$. Removed the reduction sulution 2 and added

149 imbibition solution $\left(25 \mathrm{mmol} / \mathrm{L} \mathrm{NH}_{4} \mathrm{HCO}_{3}\right)$ at room temperature for $10 \mathrm{~min}$. Removed the 
150 imbibition solution and add dehydration solution 1 for $30 \mathrm{~min}$. Removed the dehydration

151 solution 1 and added dehydration solution 2 for $30 \mathrm{~min}$. The gels were rehydrated in $10 \mu \mathrm{L}$ digest

152 solution $\left(0.02 \mu \mathrm{g} / \mu \mathrm{L}\right.$ trypsin and $\left.25 \mathrm{mM} \mathrm{NH}_{4} \mathrm{HCO}_{3}\right)$ for $30 \mathrm{~min}$ and $20 \mu \mathrm{L}$ cover solution (25

$153 \mathrm{mM} \mathrm{NH} 4 \mathrm{HCO}_{3}$ ) was added for digestion 16 hours at $37^{\circ} \mathrm{C}$ with occasional vortex mixing. The

154 solutions were added to new microcentrifuge tubes, and the gels were extracted once with $50 \mu \mathrm{L}$

155 extraction buffer (5\% TFA and $67 \%$ acetonitrile) at $37^{\circ} \mathrm{C}$ for $30 \mathrm{~min}$. The extracts were

156 thoroughly mixed with solutions and then completely dried.

157

158 Liquid chromatography-mass spectrometry. The dried samples were redissolved in

159 nano-HPLC buffer A (water solution containing 1\% $\mathrm{HCOOH}$ ), and separated using the

160 nano-HPLC liquid phase EASY-nLC1000 system. The mobile phase consisted of A liquid (water

161 solution containing $1 \% \mathrm{HCOOH}$ ) and $\mathrm{B}$ liquid (ACN solution containing 1\% $\mathrm{HCOOH}$ ). The

162 samples were loaded on a trap column of $100 \mu \mathrm{m} \times 20 \mathrm{~mm}\left(\mathrm{RP}-\mathrm{C}_{18}\right.$, Thermo $)$ with an

163 auto-sampler and separated with an analysis column $\left(75 \mu \mathrm{m} \times 150 \mathrm{~mm}, \mathrm{RP}-\mathrm{C}_{18}\right.$, Thermo $)$ at 300

$164 \mathrm{~nL} / \mathrm{min}$. Enzymatic hydrolysate was analyzed with a LTQ Orbitrap Velos Pro (Thermo Finnigan,

165 Somerset, NJ, USA), with an analysis time of $105 \mathrm{~min}$ and in cation detection mode. Data were

166 acquired using an ion spray voltage of $1.8 \mathrm{kV}$ and an interface heating temperature of $150^{\circ} \mathrm{C}$.

167 The parent ion scanning range was $350-1800 \mathrm{~m} / \mathrm{z}$. For information-dependent acquisition, the

168 strongest 15 pieces of the MS2 scan were acquired after each full scan. Fracture mode:

169 collision-induced dissociation, normal chemical energy was $35 \%$, the q value was 0.25 , and the

170 activation time was $30 \mathrm{~ms}$. Dynamic exclusion was set for $1 / 2$ of the peak width (30 s). The mass

171 spectrometry (MS) resolution was 60,000, while M/Z 400 and tandem MS (MS/MS) resolution

172 were the unit mass resolving in the ion tap. The precursor was refreshed from the exclusion list. 
173 MS using profile model collection and MS/MS using the centroid method were used to collect

174 data to reduce the file size.

175

176 Protein Identification. Based on the combined MS and MS/MS spectra, proteins were

177 successfully identified based on the $95 \%$ confidence interval of their scores in the MASCOT

178 V2.3 search engine (Matrix Science Ltd., London, UK), using the following search parameters: $S$.

179 sclerotiorum database; trypsin as the digestion enzyme; two missed cleavage sites; fixed

180 modifications of carbamidomethyl (C); partial modifications of acetyl (Protein N-term),

181 deamidated (NQ), dioxidation (W), oxidation (M); and $\pm 30 \mathrm{ppm}$ for precursor ion tolerance and

$182 \pm 0.15 \mathrm{Da}$ for fragment ion tolerance.

183

184 Bioinformatic analysis. Used the NCBInr database to obtain basic information of the identified

185 proteins from the excised gel slices. Pfam (http://pfam.sanger.ac.uk) and InterPro

186 (http://www.ebi.ac.uk/interpro/) were analyzed to find conserved domains/regions/motifs.

187 Functional categorization of proteins was analyzed with websites including UniProt

188 (http://www.uniprot.org/) and the Gene Ontology database (http://www.geneontology.org/). The

189 metabolic pathway, and which protein participated in it, was attributed to the KEGG Pathway

190 (http://www.genome.jp/kegg/pathway.html) and

EnsemblFungi

191 (http://fungi.ensembl.org/index.html).

192

\section{RESULTS AND DISCUSSION}

194 Description of sclerotial exudates and protein profiles. As described in the experimental

195 procedures, by day 6, aerial hyphae were first bestrewed on the PDA culture in a Petri dish (90 
$196 \mathrm{~mm}$ ) at $20^{\circ} \mathrm{C}$ in the dark (Fig. 1A). At the same time the aerial hyphae ceased vegetative growth

197 and started to differentiate, which was consistent with previous reports (Erental et al. 2008;

198 Patsoukis and Georgiou 2007) (Figs. 1B, 2A). After 8 days of inoculation, the obvious

199 appearance of sclerotium development was observed, with the hyphae coalesced into

200 snowball-shaped mycelia (Figs. 1C, 2B). At the same time, with the extended incubation time,

201 exudate droplets started to separate on the surface (Fig. 2C) and their quantity gradually

202 increased (Fig. 2D). At about day 12, the sclerotia were characterized by surface delimitation,

203 internal consolidation, and pigmentation, while the droplets had considerably enlarged to almost

204 the maximum amount (Figs. 1D, 2E). By day 15, the exudate droplets had completely

205 disappeared in several ways (Fig. 2F). It has been reported that, droplets can remain on the

206 surface of sclerotia for a period of time, but eventually disappear due to evaporation and

207 reabsorption (Willetts and Bullock 1992; Pandey et al. 2007). In this experiment, to collect

208 enough exudate droplets, more than 600 Petri dishes $(90 \mathrm{~mm})$ with QY-6 isolate were cultured;

209 however in other species, the collection of droplets has not been as difficult and labor-intensive

210 (Pandey et al. 2007; Aliferis and Jabaji 2010; Liang et al. 2010). This disparity was presumably

211 caused by the distinct water metabolism ability of different pathogens (Willetts and Bullock

212 1992). Another reason might be related to the moisture content of food source. Exudate droplets

213 that collected from S. ginseng exhibited water solubility and its color was light yellow. Sclerotia

214 of S. ginseng were spherical and elongated; some were aggregated to form irregular shapes, and

215 some were produced near the colony margin in concentric rings, firmly attached to the agar

216 surface (Fig. 1E). The SDS-PAGE profiles showed protein gel slices in the range of 14 and 220

$217 \mathrm{kDa}$, and the corresponding gels displayed good resolution with low background and streaking

218 (Fig. 3). 
220 Figure 1. Morphological characteristics of isolates QY-6 on potato dextrose agar after incubation

221 at $20^{\circ} \mathrm{C}$ in the dark. A, Vegetative growth of aerial hyphae. B, Initial process of differentiation.

222 C, Obvious appearance of sclerotium development. D, Collection timing. E, Maturation of

223 sclerotia characterized by surface delimitation and pigmentation.

224

225 Figure 2. The formation of exudate droplets accompany with sclerotia development of

226 Sclerotinia ginseng. A, Vegetative hyphae coalesced into mycelium, which represented the stage

227 of sclerotia initial (SI). B, Condensation of internal mycelium and enlargement of sclerotium. C,

228 During the earlier stage of sclerotia development (SD), exudate droplets began to emerge on the

229 surface of sclerotia. D, Consolidation of sclerotium with more exudate droplets separated out of

230 the sclerotial surface. E, Maturation of sclerotia characterized by surface delimitation and

231 pigmentation. F, Sclerotia mature (SM).

232

233 Figure 3. SDS-PAGE analysis of proteins present in sclerotial exudates from Sclerotinia ginseng.

234 Proteins were separated by SDS-PAGE and visualized by staining with Colloidal Coomassie

235 Blue.

236

237 Protein identification by liquid chromatography-tandem mass spectrometry. After exudate

238 droplets were fractionated and analyzed by SDS-PAGE and liquid chromatography-tandem mass

239 spectrometry (LC-MS/MS), peptide mass fingerprints of the proteins excised from gel slices

240 were evaluated to search the NCBInr database using Mascot software (www.matrixscience.com).

241 The ion score was $-10 \log (P)$, where $P$ was the probability that the observed match was a 
242 random event. Individual ion score greater than the threshold value (>33) indicated identity or

243 extensive homology $(\mathrm{p}<0.05)$. Because the exudate droplets of $S$. ginseng were not yet fully

244 annotated, the MS/MS-based identification strategy was not trivial. A total of 122 non-redundant

245 proteins were identified from the SDS-PAGE gel slices.

247 Functional categories and proteome mining data. So far, the complete genome sequences of $S$.

248 ginseng has not been studied, which leads a certain limitation in the search for identification of

249 exudate droplets proteome. However, the complete genome sequences of closely related species

250 of S. sclerotiorum and B. cinerea are openly available in the database that can be used as a

251 reliable reference to identify the exudate droplets proteome of $S$. ginseng. Based on the available

252 search databases, a total of 122 proteins were calculated from exudation of $S$. ginseng, and only

25359 proteins individual ion scores satisfied the conditions (threshold value $>33$ ) (Table 1). The

254 identified proteins were classified into six groups according to their characteristics based on GO

255 terms analysis. The major functional groups were carbohydrate metabolism (39\%),

256 oxidation-reduction process (12\%), transport and catabolism (5\%), amino acid metabolism (3\%),

257 other functions (18\%), and unknown protein (23\%) (Fig. 4).

258

259 Table 1. List of Proteins Identified by SDS-PAGE with LC-MS/MS in the Sclerotial Exudates

260

261 Figure 4. Functional classification of proteins identified in sclerotial exudates from Sclerotinia 262 ginseng.

263 During the development of S. ginseng, it was not difficult to find that the development and

264 maturation of this pathogen accompanied with huge morphological changes especially in 
265 remodeling fungal cell wall. The fungal cell wall is pivotal for cell shape and function and acts as

266 an interfacial protective barrier during host infection and environmental challenge (Samalova et

267 al. 2017). Most fungal cell walls consist of a crosslinked matrix of glucans, chitins, and cell wall

268 proteins (Ao et al. 2016). According to the results, proteins of the carbohydrate metabolic

269 process (39\%) of exudate droplets accounted for the largest proportion, which consistent with a

270 previous study (Liang et al. 2010). Among this group, most of them belonged to glycoside

271 hydrolase family members, which mainly had functions of glucanase activity (gi|154703817|,

272 gi|154701174|, gi|347832626|) and chitinase activity (gi|154691632|). Some of them also are

273 identified with the research of Liang (Liang et al. 2010). Ao et al. (2016) demonstrate that the

274 NGA-1 exo-chitinase and the CGL-1 $\beta$-1,3-glucanase, play critical roles in remodeling the

275 Neurospora crassa conidia cell walls. Chitinase also involves in the process of cell wall

276 formation by modifying cell wall architecture during hyphal growth in Neurospora crassa

277 (Tzelepis et al. 2012). It may be suggested that some proteins in carbohydrate metabolic process

278 group has assisted in formation of fungal cell walls. Colotelo (1978) also indicated that the

279 droplets were associated with actively growing mycelia. Samalova et al. (2017) characterizes

280 five putative $\beta$-1,3-glucan glucanosyltransferases play significant roles in structural modification

281 of the cell wall of Magnaporthe oryzae during appressorium-mediated plant infection.

282 Glucanosyltransferases (gi|154694741|, gi|154697112|, gi|154698335|, gi|154698875|) had also

283 been identified in carbohydrate metabolism group of exudate droplets and the protein

284 (gi|154694741|) possesses the role in elongation of 1,3-beta-glucan chains (Mouyna et al. 2000)

285 which further certifies the role in modifying cell wall structure. Some other proteins including

286 a-mannosidase (gi|347830055|, gi|154702253|) (Rajesh et al. 2014) and rhamnosidase

287 (gi|154702326|) identified in this group were also reported to participate in modifying cell wall 
288 architecture (Ichinose et al. 2013). As aforementioned, most proteins in this group participated in

289 formation of the fungal cell wall (Martens-Uzunova et al. 2006; Tzelepis et al. 2012; Ao et al.

290 2016; Samalova et al. 2017). The amount of carbohydrate compounds might be related to the

291 regulation of coenzymes, which could continue oxidizing the sugar material to provide energy

292 and carbon skeleton for the development of sclerotia.

293 Additionally, two proteins were identified to occupy pectinase activity (gi|154705171|,

294 gi|347830059|) and three proteins played a role in cellulase activity (gi|347836311|,

295 gi|154693234|, gi|347836319|). Cellulose, hemicellulose, and pectin are three main components

296 of the plant cell wall that compose an important barrier against pathogen attack. To succeed in

297 infecting plants, fungi possess a diverse array of secreted enzymes (e. g. pectinase, cellulase) to

298 depolymerize the main structural polysaccharide of cell wall (Kubicek et al. 2014). It is

299 suggested that these five proteins may be existence as a virulence factor factor of this fungus.

300 Cellulolytic and polygalacturonase activities for the exudate and sclerotial extracts were also

301 demonstrated in previous study (Colotelo et al. 1971).The observation further can be speculated

302 that exudate droplets of the fungi possess pathogenicity which is involved in maceration and

303 soft-rotting of plant tissue.

304 Accounting for the second largest protein component was the unknown protein group (23\%);

305 thus, these proteins should not be overlooked as they were present in significant amounts. In this

306 category, there was a development-specific protein (Ssp1) (gi|238477235|), which also appeared

307 in the exudate droplets of S. sclerotiorum (Liang et al. 2010). Although its function is unknown,

308 it is the most abundant soluble protein in sclerotia and apothecia of S. sclerotiorum (Li and

309 Rollins 2010). The ssp1 transcript accumulates exclusively within developing sclerotium tissue

310 and not in any other examined stage of growth or development. (Li and Rollins 2009). It can be 
311 speculated that Ssp1 maybe a critical protein during the later stage of sclerotial development in

312 Sclerotiniaceae family. Outside the Sclerotiniaceae sspl homologs are found only from the

313 sclerotium-forming Aspergillus species A. flavus and A. oryzae. (Li and Rollins 2009), which

314 further illustrates the characteristic of it. Therefore, additional studies concerning the regulation,

315 function, and mechanism of this protein would lead to a better understanding of sclerotium

316 development. Currently, there has been increasing research about unknown functions, as these

317 studies can provide a basis for understanding the regulation of biological processes.

318 Another major category that was identified was oxidation-reduction process (12\%), which is

319 an important part of the exudate droplet proteome. Four proteins were identified or similar to

320 laccase (gi|154697664|, gi|347840672|, gi|154704145|, gi|154702896|) and has been shown to be

321 mainly involved in lignin biodegradation, fungal virulence, morphogenesis and melanin

322 synthesis (Coman et al. 2013). In the exudate droplets of S. sclerotiorum only laccase

323 (gi|154702896|) had been identified. Tyrosinase (gi|154696912|) was also found in this group,

324 which has a critical role in formation of pigments such as melanin and other polyphenolic

325 compounds (Stevens et al. 1998; Mahendra Kumar et al. 2011). Melanin, which plays an

326 important role in the process of sclerotium formation, has been extensively studied, and allows

327 the dormancy of fungal propagules by protecting them against a variety of unfavorable

328 conditions (Butler et al. 2005). It is also a critical factor affecting the pathogenicity of pathogens

329 (Butler et al. 2005; Abo Ellil 1999).

330 A small proportion but equally important proteome can not be ignored, which also possesses

331 significant functions. In mycotoxin biosynthetic process, oxidase ustYa is involved in the the

332 production of ustiloxins, toxic cyclic peptides, in filamentous fungi, which wasn't identified in

333 the exudate droplets of $S$. sclerotiorum. Ustiloxins are found recently to be the first example of 
334 cyclic peptidyl secondary metabolites that are ribosomally synthesized in filamentous fungi

335 (Nagano et al. 2016), which can be suggested that exudate droplets of S. ginseng may participate

336 in the biosynthesis of toxin or involve in pathogenicity and virulence.

337 Although most proteins of exudate droplets of $S$. sclerotiorum (Liang et al. 2010) and $S$.

338 ginseng were calculated from the available search database of S. sclerotiorum, there were only

33915 proteins presented in the two identified proteomes and most of them belonged to carbohydrate

340 metabolic process. It was suggested that although the two pathogens all belonged to

341 Sclerotiniaceae, but the difference was still a considerable quantity. Therefore, it is of great

342 significance to study the exudate droplets of $S$. ginseng. With the further deepening of the

343 research on Sclerotiniaceae, the function of some unknown proteins has been gradually revealed,

344 which can be reflected on the proportion of unknown protein group in the exudate droplets.

345 Compared to the unknown proteins (32\%) of exudate droplets in S. sclerotiorum (Liang et al.

346 2010), the proportion of unknown proteins of exudate droplets in S. ginseng had decreased to

$34723 \%$. According to our results, more abundant categories were classified in other proteome group

348 including protein binding, $\mathrm{N}$-acetyltransferase activity, phospholipid biosynthetic process, chitin

349 binding, ATP binding, ubiquitin-protein transferase activity, nucleic acid binding, mycotoxin

350 biosynthetic process and energy metabolism, which could reflect functional diversity of exudate

351 droplets indirectly.

352 In conclusion, future studies should be performed about the metabolic pathway and

353 functions of the exudate droplets using modern techniques. In addition, because the proportion of

354 unknown protein components was still relatively high in this study, they should also be the focus

355 of future studies. 
357 ADDITIONAL INFORMATION AND DECLARATIONS

358

359 REFERENCES

360 Abo Ellil, A. H. A. 1999. Oxidative stress in relation to lipid peroxidation, sclerotial development

361 and melanin production by Sclerotium rolfsii. Journal of Phytopathology. 147: 561-566.

362 Adams, P. B. and Ayers, W. A. 1979. Ecology of Sclerotinia species. Phytopathology.

$363 \quad 69: 896-899$.

364 Aliferis, K. A. and Jabaji, S. 2010. Metabolite Composition and Bioactivity of Rhizoctonia solani

365 Sclerotial Exudates. J. Agric. Food Chem. 58: 7604-7615.

366 Ao, J., Aldabbous, M., Notaro, M. J., Lojacono, M. and Free, S. J. 2016. A proteomic and genetic

367 analysis of the Neurospora crassa conidia cell wall proteins identifies two glycosyl

368 hydrolases involved in cell wall remodeling. Fungal Genet Biol. 94: 47-53.

369 Butler, M. J., Gardiner, R. B. and Day, A. W. 2005. Degradation of melanin or inhibition of its

370 synthesis: are these a significant approach as a biological control of phytopathogenic fungi?

$371 \quad$ Biological Control. 32: 326-336.

372 Chet, I. and Henis, Y. 1975. Sclerotial morphogenesis in fungi. Ann. Rev. Phytopathol. 13:

$373 \quad 169-192$.

374 Cho, H. S.,Shin, J. S.,Kim, J. H.,Hong, T. K. 2013. First Report of Sclerotinia White Rot Caused

375 by Sclerotinia nivalis on Panax ginseng in Korea. Research in Plant Disease. 19: 49-54.

376 Colotelo, N. 1971. Chemical studies on the exudate and developing sclerotia of Sclerotinia 377 sclerotiorum (Lib.) De Bary. Can. J. Microbiol. 17: 1189-1194.

378 Colotelo, N. 1973. Physiological and biochemical properties of the exudate associated with 379 developing sclerotia of Sclerotinia sclerotiorum (Lib.) De Bary. CAN. J. MLCROBIOL. 19: 
73-79.

381 Colotelo, N. 1978. Fungal exudates. Canadian Journal of Microbiology. 24: 1173-1181.

382 Colotelo, N., Sumner, J. L. and Voegelin, W. S. 1971. Presence of sacs enveloping the liquid 383 droplets on developing sclerotia of Sclerotinia sclerotiorum (Lib.) de Bary. Canadian $384 \quad$ Journal of Microbiology. 17: 300-301.

385 Coman, C., MOŢ, A. C., Gal, E., Pârvu, M. and Silaghi-Dumitrescu, R. 2013. Laccase is 386 upregulated via stress pathways in the phytopathogenic fungus Sclerotinia sclerotiorum. $387 \quad$ Fungal Biology. 117: 528-539.

388 Cooke, R. C. 1969. Changes in soluble carbohydrates during sclerotium formation by Sclerotinia 389 sclerotiorum and S. trifoliorum. Trans. Br. Mycol. Soc. 53: 77-86.

390 Daly, H., Knoche, H. W. and Wiese M. V. 1967. Carbohydrate and lipid metabolism during 391 germination of uredospores of Puccinia graminis tritici. Physiol. 42: 1633-1642.

392 Erental, A., Dickman, M. B. and Yarden, O. 2008. Sclerotial development in Sclerotinia 393 sclerotiorum: awakening molecular analysis of a Dormant structure. Fungal biology reviews. $394 \quad 22: 6-16$.

395 Han, H., Chen, Y., Bi, H. T., Yu, L., Sun C. X., Li, S. S., Oumar S. A. and Zhou, Y. F. 2011. In 396 vivo antimalarial activity of ginseng extracts. Pharmaceutical Biology. 49: 283-289.

397 Ichinose, H., Fujimoto, Z., Kaneko, S. 2013. Characterization of an $\alpha$-L-Rhamnosidase from 398 Streptomyces avermitilis. Biosci. Biotechnol. Biochem. 77: 213 - 216.

399 Jiao, L. L., Zhang, X. Y., Wang, M. Z., Li, B., Liu, Z. and Liu, S. Y. 2014. Chemical and 400 antihyperglycemic activity changes of ginseng pectin induced by heat processing. $401 \quad$ Carbohydrate Polymers. 114: 567-573.

402 Jones, D. 1970. Ultrastructure and composition of the cell walls of Sclerotinia sclerotiorum. 
Trans. Br. SOC. 54: 351-360.

404 Katayama, H., Nagasu, T. and Oda, Y. 2001. Improvement of in-gel digestion protocol for 405 peptide mass fingerprinting by matrix-assisted laser desorption/ionization time-of-flight 406 mass spectrometry. Rapid Communications in Mass Spectrometry. 15: 1416-1421.

407 Kubicek, C. P., Starr, T. L., Glass, N. L. 2014. Plant Cell Wall-Degrading Enzymes and Their 408 Secretion in Plant-Pathogenic Fungi. Annual Review of Phytopathology. 52: 427-451.

409 Kwon, Y. S., Kim, S, G., Chung, W. S., Bae, H., Jeong, S. W., Shin, S. C., Jeong, M. J., Park, S.

410 C., Kwak, Y. S., Bae, D. W. and Lee, Y. B. 2014. Proteomic analysis of Rhizoctonia solani 411 AG-1 sclerotia maturation. Fungal Biology. 118: 433-443.

412 Li, M. Y. and Rollins, J. A. 2009. The development-specific protein (Ssp1) from Sclerotinia 413 sclerotiorum is encoded by a novel gene expressed exclusively in sclerotium tissues. $414 \quad$ MYCOLOGIA. 101: 34-43.

415 Li, M. Y. and Rollins, J. A. 2010. The development-specific ssp1 and ssp2 genes of Sclerotinia 416 sclerotiorum encode lectins with distinct yet compensatory regulation. Fungal Genetics and $417 \quad$ Biology. 47: 531-538

418 Liang, Y., Strelkov, S. E. and Kav, N. N. V. 2010. The proteome of liquid Sclerotial exudates 419 from Sclerotinia sclerotiorum. Journal of Proteome Research. 9: 3290-3298.

420 Mahendra Kumar, C., Sathisha, U. V., Dharmesh, S., Appu Rao, A. G. and Singh, S. A. 2011. 421 Erratum to "Interaction of sesamol (3,4-methylenedioxyphenol) with tyrosinase and its 422 effect on melanin synthesis”. Biochimie. 93: 562-569.

423 Martens-Uzunova, E. S., Zandleven, J. S., Benen, J. A. E., Awad, H., Kools, H. J., Beldman, G., 424 Voragen, A. G. J., Van Den Berg, J. A. and Schaap, P. J. 2006. A new group of exo-acting 425 family 28 glycoside hydrolases of Aspergillus niger that are involved in pectin degradation. 
427 Mouyna, I., Fontaine, T., Vai, M., Monod, M., Fonzi, W. A., Diaquin, M., Popolo, L., Hartland, R.

428 P., Latge, J. P. 2000. Glycosylphosphatidylinositol-anchored glucanosyltransferases play an

429 active role in the biosynthesis of the fungal cell wall. The Journal of Biological Chemistry.

$430 \quad 275: 14882-14889$.

431 Nagano, N., Umemura, M., Izumikawa, M., Kawano, J., Ishii, T., Kikuchi, M., Tomii, K., 432 Kumagai, T., Yoshimi, A., Machida, M., Abe, K., Shin-Ya, K., Asai, K. 2016. Class of cyclic 433 ribosomal peptide synthetic genes in filamentous fungi. Fungal Genet Biol. 86: 58-70.

434 Pandey, M. K., Sarma, B. K., Singh, D. P. and Singh, U. P. 2007. Biochemical Investigations of 435 Sclerotial Exudates of Sclerotium rolfsii and their Antifungal Activity. 155: 84-89.

436 Patsoukis, N. and Georgiou, C. D. 2007. Effect of thiol redox state modulators on oxidative 437 438 Archives of Microbiology. 188: 225-233.

439 Rajesh T., Jeon, J. M., Song, E., Park, H. M., Seo, H. M., Kim, H. J., Yi, D. H., Kim, Y. H., 440 Choi, K. Y., Kim, Y. G., Park, H. Y., Lee, Y. K., Yang, Y. H. 2014. Putative Role of a 441 Streptomyces coelicolor-Derived $\alpha$-Mannosidase in Deglycosylation and Antibiotic 442 Production. Applied Biochemistry and Biotechnology. 172: 1639-1651.

443 Samalova, M., Mélida, H., Vilaplana, F., Bulone, V., Soanes, D. M., Talbot, N. J. and Gurr, S. J. 444 2017. The $\beta$-1,3-glucanosyltransferases (Gels) affect the structure of the rice blast fungal 445 cell wall during appressorium-mediated plant infection. Cellular Microbiology. 19: e12659.

446 Singh, U. P., Sarma, B. K., Singh, D. P. and Bahadur, A. 2002. Studies on exudate-depleted 447 sclerotial development in Sclerotium rolfsii and the effect of oxalic acid, sclerotial exudate, 448 and culture filtrate on phenolic acid induction in chickpea (Cicer arietinum). Can. J. 
$449 \quad$ Microbiol. 48: 443-448.

450 Stevens, L. H., Davelaar, E., Kolb, R. M., Pennings, E. J. M. and Smit, N. P. M. 1998. Tyrosine 451 and cysteine are substrates for blackspot synthesis in potato. Phytochemistry. 49: 703-707.

452 Sun, Y. X. 2011. Structure and biological activities of the polysaccharides from the leaves, roots 453 and fruits of Panax ginseng C.A. Meyer: An overview. Carbohydrate Polymers. 85: $454 \quad 490-499$.

455 Tzelepis, G. D., Melin, P., Jensen, D. F., Stenlid, J. and Karlsson, M. 2012. Functional analysis of 456 glycoside hydrolase family 18 and 20 genes in Neurospora crassa. Fungal Genetics and 457 Biology. 49: 717-730.

458 Wan, J. Y., Fan Y., Yu, Q. T., Ge, Y. Z. and Yan, C. P., Alolga, R. N., Li, P., Ma, Z. H. and Qi, L. 459 W. 2015. Integrated evaluation of malonyl ginsenosides, amino acids and polysaccharides in 460 fresh and processed ginseng. Journal of Pharmaceutical and Biomedical Analysis. 107: $461 \quad 89-97$.

462 Wang, H. P., Zhang, Y. B., Yang, X. W., Yang, X. B., Xu, W., Xu, F., Cai, S. Q., Xu, Y. P., Xu, Y. 463 H. and Zhang, L. X. 2016. High-Performance Liquid Chromatography with Diode Array 464 Detector and Electrospray Ionization Ion Trap Time-of-Flight Tandem Mass Spectrometry 465 to Evaluate Ginseng Roots and Rhizomes from Different Regions. Molecules. 21: 050603.

466 Willetts, H. J. 1971. The survival of fungal sclerotia under adverse environmental conditions. 467 Biol. Rev. 46: 387-407.

468 Willetts, H. J. and Bullock, S. 1992. Developmental biology of sclerotia. Mycol. Res. 96: $469 \quad 801-816$

470 Yu, X. N., Yang, X. S., Cui, B., Wang, L. J. and Ren, G. X. 2014. Antioxidant and 471 immunoregulatory activity of alkali-extractable polysaccharides from North American 
472 ginseng. International Journal of Biological Macromolecules. 65: 357-361.

473 Zhou, X., Shi, H, Y., Jiang, G. N., Zhou, Y. A. and Xu, J. F. 2014. Antitumor activities of ginseng 474 polysaccharide in C57BL/6 mice with Lewis lung carcinoma. Tumour Biology. 35: $475 \quad 12561-12566$. 


\section{Figure 1}

Morphological characteristics of isolates QY-6 on potato dextrose agar after incubation at $20^{\circ} \mathrm{C}$ in the dark.

A, Vegetative growth of aerial hyphae. B, Initial process of differentiation. C, Obvious appearance of sclerotium development. D, Collection times. E, Maturation of sclerotia characterized by surface delimitation and pigmentation.

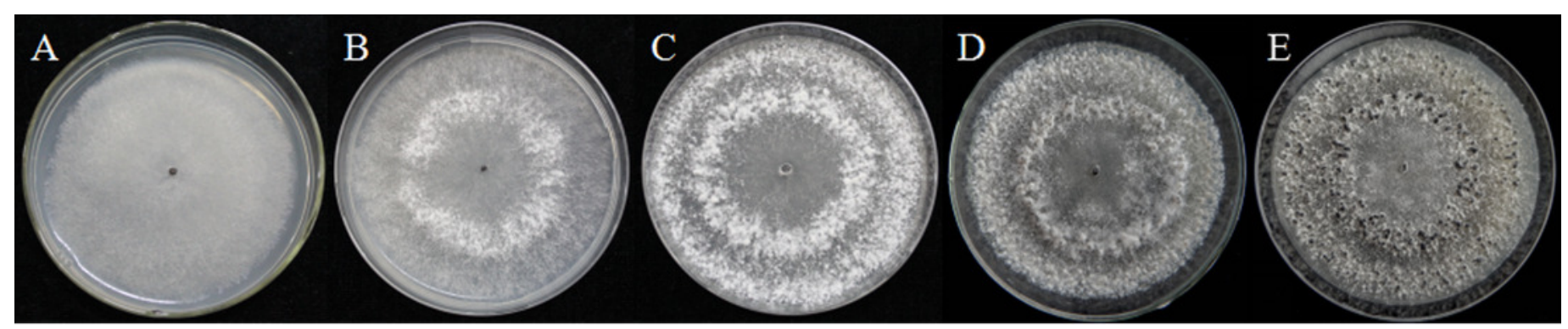




\section{Figure 2}

The formation of exudate droplets accompanying sclerotia development of Sclerotinia ginseng.

A, Vegetative hyphae coalesced into mycelia, which represented the stage of sclerotia initial (SI). B, Condensation of internal mycelium and enlargement of sclerotium. C, During the earlier stage of sclerotia development (SD), exudate droplets began to emerge on the surface of the sclerotia. D, Consolidation of sclerotium with more exudate droplets separated out of the sclerotial surface. E, Maturation of sclerotia characterized by surface delimitation and pigmentation. $\mathbf{F}$, Sclerotia mature (SM).

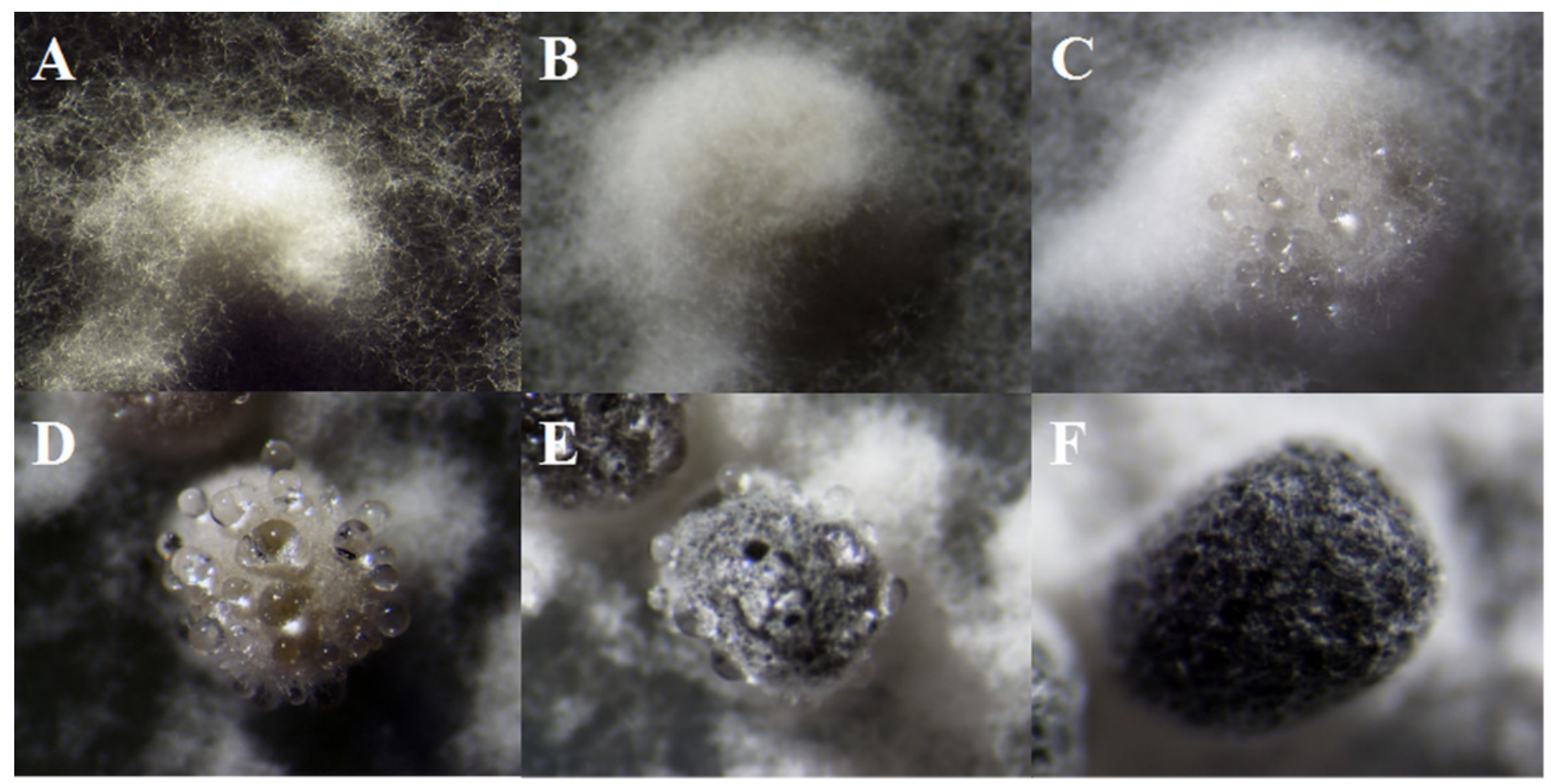




\section{Figure 3}

Functional classification of proteins identified in sclerotial exudates from Sclerotinia ginseng.

Proteins were separated by SDS-PAGE and visualized by staining with colloidal Coomassie blue. 


\section{Exudate}

$220 \mathrm{KD}$

$90 \mathrm{KD}$

$66 \mathrm{KD}$

$40 \mathrm{KD}$

$35 \mathrm{KD}$

$29 \mathrm{KD}$

$20 \mathrm{KD}$ 


\section{Figure 4}

Functional classification of proteins identified in sclerotial exudates from Sclerotinia ginseng.

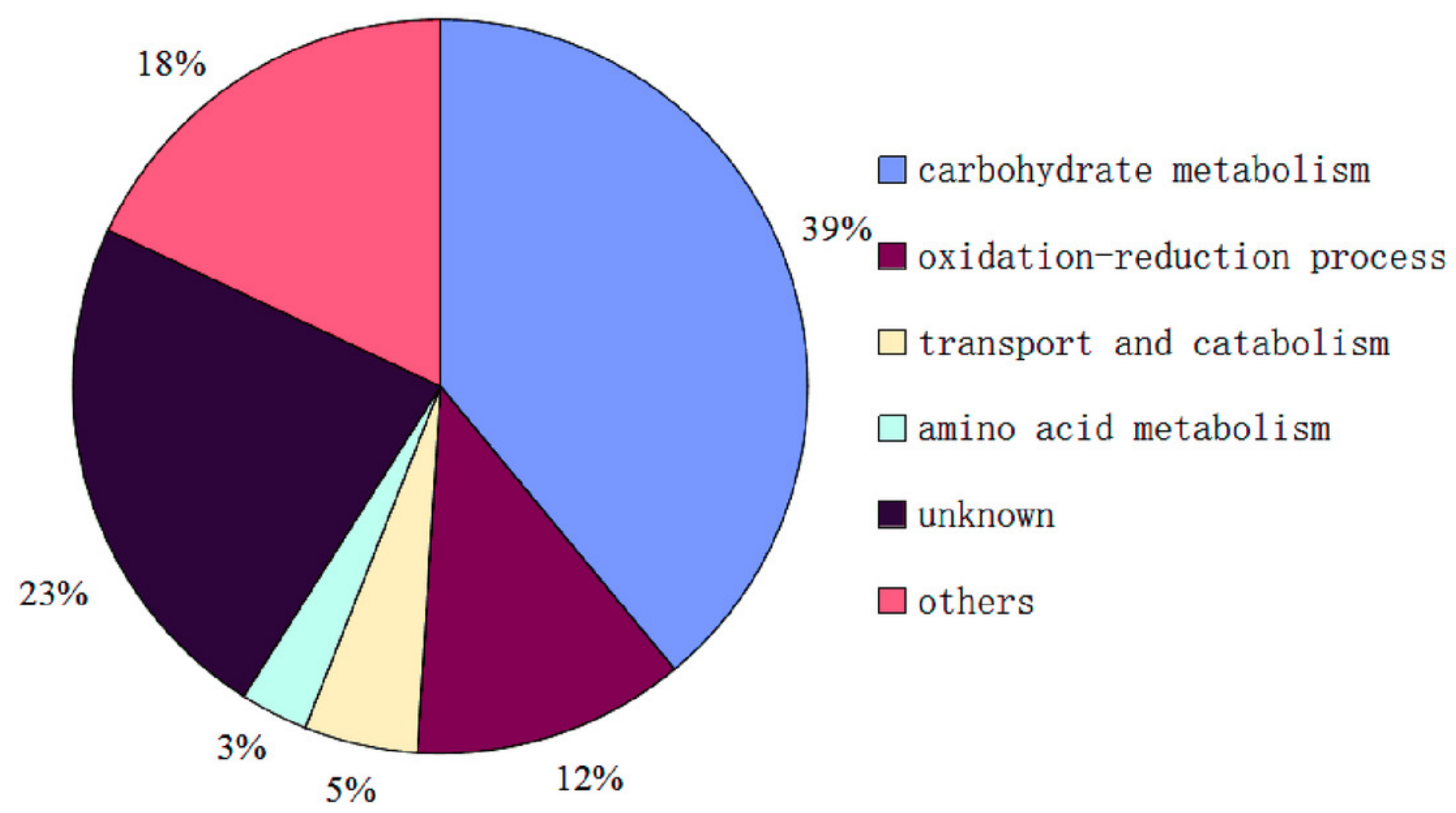




\section{Table 1 (on next page)}

List of proteins identified by SDS-PAGE with LC-MS/MS in the sclerotial exudates 
1 TABLE 1. List of Proteins Identified by SDS-PAGE with LC-MS/MS in the Sclerotial Exudates

\begin{tabular}{|c|c|c|c|c|c|c|}
\hline $\mathbf{G I}^{\mathbf{a}}$ & Protein name ${ }^{b}$ & Score $^{\mathrm{c}}$ & Mass $^{d}$ & Matches $^{\text {e }}$ & Sequences $^{f}$ & emPAI ${ }^{g}$ \\
\hline & Carbohydrate metabolic process & & & & & \\
\hline gi $|347830055|$ & glycoside hydrolase family 92 protein & 513 & 86256 & $16(11)$ & $7(4)$ & 0.16 \\
\hline gi|$|154705171|$ & hypothetical protein SS1G_07393 & 260 & 83872 & $12(8)$ & $7(3)$ & 0.12 \\
\hline gi|$|154703817|$ & glucan 1,3-beta-glucosidase SS̄1G_06037 & 231 & 46611 & $20(10)$ & $9(6)$ & 0.61 \\
\hline gi $|154695005|$ & glucoamylase SS1G_10617 & 225 & 72488 & $11(8)$ & $4(2)$ & 0.09 \\
\hline gi $|1095456302|$ & glucoamylase sscle_10 $1 \bar{g} 080270$ & 212 & 67612 & $8(4)$ & $5(2)$ & 0.1 \\
\hline gi $|154694741|$ & 1,3-beta-glucanosyltransferase SS1G_10353 & 198 & 47929 & $12(7)$ & $7(4)$ & 0.3 \\
\hline gi| $154694427 \mid$ & beta-hexosaminidase SS1G_10038 & 161 & 64156 & $13(6)$ & $6(4)$ & 0.22 \\
\hline gi $|154702253|$ & alpha-1,2-Mannosidase SS1G__04468 & 123 & 58064 & $6(5)$ & $4(4)$ & 0.25 \\
\hline gi $|154701174|$ & hypothetical protein SS1G_03387 & 117 & 63029 & $3(3)$ & $2(2)$ & 0.11 \\
\hline gi $|347832626|$ & glycoside hydrolase family $\overline{71}$ protein & 102 & 81772 & $2(1)$ & $2(1)$ & 0.04 \\
\hline gi $|154702326|$ & hypothetical protein SS1G_04541 & 84 & 78092 & $11(5)$ & $7(4)$ & 0.18 \\
\hline gi $\mid 154698322$ & hypothetical protein SS1G_-12917 & 83 & 43069 & $5(2)$ & $2(2)$ & 0.16 \\
\hline gi $|154697112|$ & hypothetical protein SS1G_01776 & 71 & 49311 & $3(3)$ & $2(2)$ & 0.14 \\
\hline gi $|154698335|$ & $\begin{array}{l}\text { glycoside hydrolase family } 17 \text { protein } \\
\text { SS1G_12930 }\end{array}$ & 63 & 31996 & $3(2)$ & $2(2)$ & 0.22 \\
\hline gi|347836311| & glycoside hydrolase family 3 protein & 56 & 94046 & $7(3)$ & $5(3)$ & 0.11 \\
\hline gi $|154691568|$ & transaldolase SS1G_00709 & 53 & 31398 & $1(1)$ & $1(1)$ & 0.11 \\
\hline gi $|154698875|$ & hypothetical protein $\mathrm{SS}_{\bar{S}} \mathrm{G}_{-} 13472$ & 48 & 60572 & $2(1)$ & $2(1)$ & 0.05 \\
\hline gi|507414638| & $\begin{array}{c}\text { carbohydrate-Binding Module family } 20 \\
\text { protein }\end{array}$ & 46 & 43095 & $3(1)$ & $2(1)$ & 0.08 \\
\hline gi $|154693234|$ & hypothetical protein SS1G_08837 & 40 & 44896 & $1(1)$ & $1(1)$ & 0.07 \\
\hline gi $|154693514|$ & hypothetical protein SS1G_09118 & 38 & 33973 & $1(1)$ & $1(1)$ & 0.1 \\
\hline gi $|347830059|$ & glycoside hydrolase family $\overline{28}$ protein & 38 & 39845 & $2(2)$ & $1(1)$ & 0.08 \\
\hline gi $|154691632|$ & hypothetical protein SS1G_00773 & 36 & 190114 & $6(1)$ & $4(1)$ & 0.02 \\
\hline gi|347836319| & $\begin{array}{l}\text { glycoside hydrolase family } \overline{3} \text { protein } \\
\text { Unknown protein }\end{array}$ & 35 & 95468 & $3(1)$ & $2(1)$ & 0.03 \\
\hline gi|1095449307| & hypothetical protein sscle_01g010410 & 1206 & 87452 & $74(51)$ & $8(7)$ & 0.55 \\
\hline gi $|238477235|$ & developmental-specific protein Ssp1 & 915 & 35067 & $86(45)$ & $17(13)$ & 5.09 \\
\hline gi $|1095455875|$ & hypothetical protein sscle_10g076000 & 181 & 112854 & $10(8)$ & $6(4)$ & 0.15 \\
\hline gi $|154696190|$ & predicted protein $\mathrm{SS} 1 \overline{\mathrm{G}}_{-} 12133$ & 170 & 37138 & $16(7)$ & $7(5)$ & 0.53 \\
\hline gi $|154705040|$ & hypothetical protein $\mathrm{SS} 1 \overline{\mathrm{G}} \_07262$ & 163 & 23894 & $6(4)$ & $2(2)$ & 0.3 \\
\hline gi $|154696764|$ & hypothetical protein SS1G_01428 & 105 & 45622 & $6(6)$ & $2(2)$ & 0.15 \\
\hline gi $|154704206|$ & hypothetical protein SS1G_06426 & 95 & 95078 & $6(4)$ & $4(2)$ & 0.07 \\
\hline gi $|1095455126|$ & hypothetical protein sscle_08g068530 & 91 & 62168 & $9(3)$ & $6(2)$ & 0.11 \\
\hline gi|347831150| & hypothetical protein BofuT4_P115530.1 & 67 & 41337 & $1(1)$ & $1(1)$ & 0.08 \\
\hline gi $|154700524|$ & hypothetical protein $\mathrm{SS} 1 \bar{G}_{-} 14133$ & 60 & 32906 & $6(3)$ & $3(1)$ & 0.1 \\
\hline gi $|347827005|$ & hypothetical protein BofuT4_P 073140.1 & 47 & 66587 & $2(2)$ & $2(2)$ & 0.1 \\
\hline gi $|347838722|$ & hypothetical protein BofuT4_P123130.1 & 40 & 21674 & $2(2)$ & $1(1)$ & 0.16 \\
\hline gi $|154691708|$ & hypothetical protein SS1G__o0849 & 38 & 16672 & $2(2)$ & $1(1)$ & 0.2 \\
\hline gi $|154693400|$ & $\begin{array}{l}\text { predicted protein } S S 1 G \_09003 \\
\text { Oxidation-reduction process }\end{array}$ & 33 & 7259 & $3(1)$ & $1(1)$ & 0.49 \\
\hline gi|154697664| & hypothetical protein SS1G_11927 & 448 & 70689 & $14(11)$ & $4(4)$ & 0.37 \\
\hline gi|$|1095450409|$ & hypothetical protein sscle_02 02021420 & 160 & 64659 & $8(4)$ & $6(3)$ & 0.16 \\
\hline
\end{tabular}




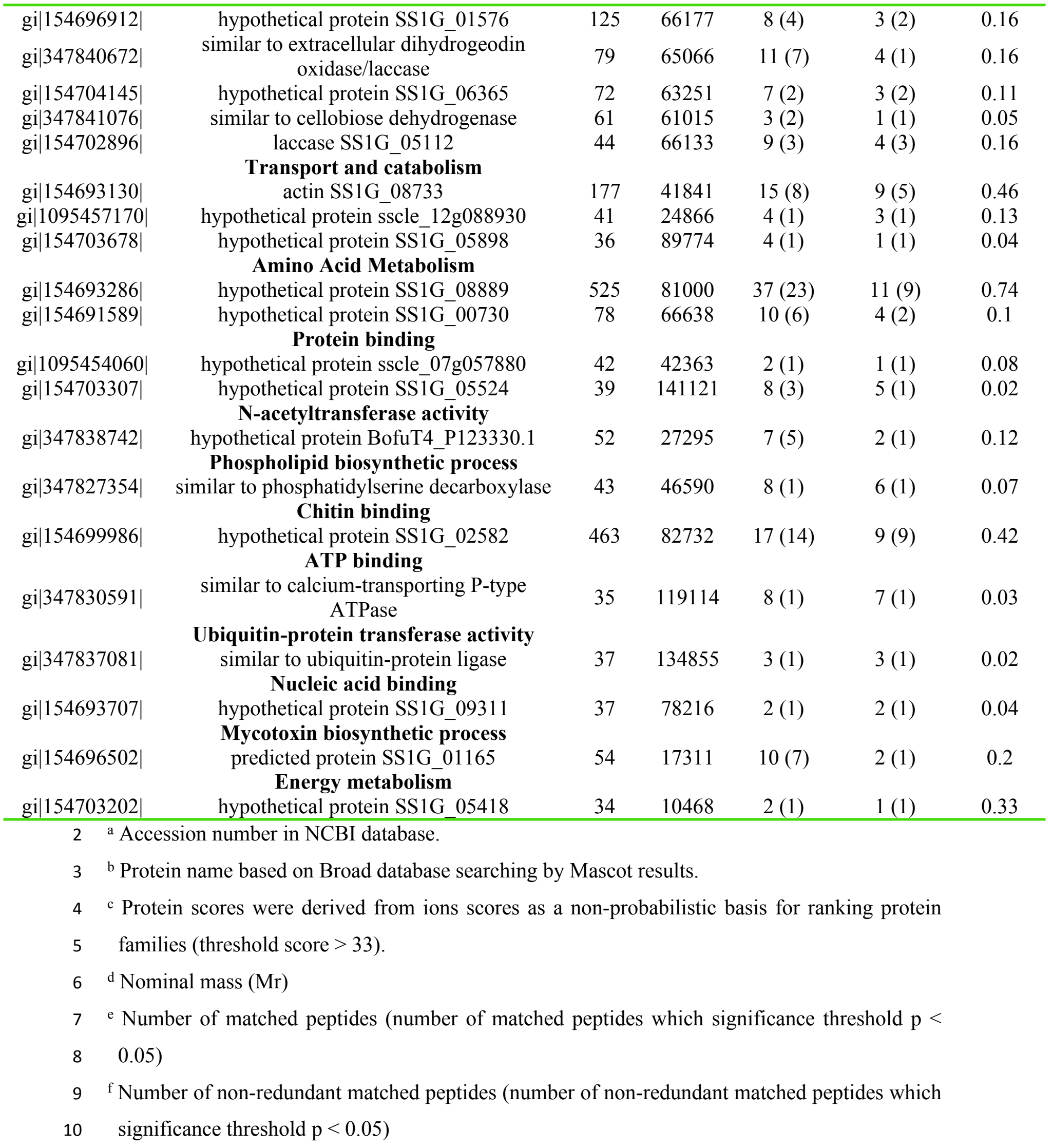


11 g Protein abundance value

12 